\title{
Avaliação da produção de biogás obtido a partir de dejeto bovino e casca de café
}

\section{Evaluation of biogas production obtained from bovine manure and coffee husk}

\author{
Verônica Aparecida Ferrari Fumian ${ }^{1}$, Tayná da Silva Picanço ${ }^{1}$, Luís Paulo Fonseca \\ Porto ${ }^{2}$, Camila de Paula Bandoli Gomes ${ }^{1}$, Adriano Henrique Ferrarez ${ }^{3 *}$
}

\footnotetext{
${ }^{1}$ Técnica em Química, Instituto Federal Fluminense, Campus Itaperuna, RJ, Brasil

${ }^{2}$ Técnico em Química, Instituto Federal Fluminense, Campus Itaperuna, RJ, Brasil

${ }^{3}$ Professor do Instituto Federal Fluminense, Campus Itaperuna, RJ, Brasil

*Autor para correspondência, E-mail: aferrarez@iff.edu.br
}

Received: 19 August 2020 | Accepted: 02 December 2020 | Published online: 04 February 2021

Resumo: A bovinocultura e a cafeicultura possuem uma grande participação no Produto Interno Bruto (PIB) brasileiro. Essas atividades, entretanto, produzem grande quantidade de resíduos que causam grandes impactos ambientais. A digestão anaeróbica se apresenta como solução no gerenciamento desses resíduos, resultando na produção de biogás e biofertilizante. O objetivo deste trabalho foi avaliar a produção e o teor de metano (CH4) do biogás obtido a partir de dejeto bovino e casca de café. Utilizou-se duas triplicatas de digestores de bancada, a saber: (i) D1 - dejeto bovino (1 Litro); e (ii) D2 - dejeto bovino e casca de café (1 Litro: 1 Litro). Semanalmente foram realizadas as medições do volume e do teor de metano (CH4) do biogás produzido. Ao final do experimento foi realizada a medição do $\mathrm{pH}$ do material remanescente em cada digestor anaeróbico. Observou-se que a triplicata D2 apresentou produção acumulada de biogás com teores médios de $\mathrm{CH} 4$ maiores que a triplicata $\mathrm{D} 1$. $\mathrm{O} \mathrm{pH}$ se apresentou na faixa ótima para o processo anaeróbico em todos os digestores.

Palavras chave: energia renovável, codigestão anaeróbica, sustentabilidade.

\begin{abstract}
Cattle and coffee farming have a significant share in the Brazilian Gross Domestic Product $(G D P)$. These activities, however, produce large amounts of waste that cause significant environmental impacts. Anaerobic digestion presents itself as a solution in the management of this waste, resulting in the production of biogas and biofertilizer. This work's objective was to evaluate the production and methane content (CH4) of the biogas obtained from bovine manure and coffee husk. Used two benchtop digesters triplicates: (i) D1 - bovine manure (1 Liter); and (ii) D2 - bovine manure and coffee husk (1 Liter: 1 Liter). Performed measurements of the volume and methane content (CH4) of the biogas produced weekly. They measured the $\mathrm{pH}$ of the remaining material in each anaerobic digester at the end of the experiment. The D2 triplicate showed accumulated biogas production with average CH4 contents higher than the D1 triplicate. The $\mathrm{pH}$ was in the optimum range for the anaerobic process in all digesters.
\end{abstract}

Keywords: renewable energy, anaerobic codigestion, sustainability.

\section{Introdução}

O Brasil é o maior produtor e exportador mundial de café, atividade que juntamente com a bovinocultura possuem grande participação no Produto Interno Bruto (PIB) do país (Fernandes e Oliveira, 2006). Entretanto, a agropecuária gera uma grande quantidade de resíduos que causam contaminação do solo, de lençóis freáticos, além de espalhar agentes patológicos (Orrico et al., 2007). Tais contaminantes são os grandes responsáveis por doenças respiratórias, de cunho intestinal e também epidêmicas (Konzen, 1983; Amaral et al., 2004).

A digestão anaeróbica se apresenta como solução para o tratamento dos resíduos agropecuários com produção de biogás e biofertilizante. 
O biogás é o gás produzido por meio da decomposição de matéria orgânica a partir de microrganismos anaeróbicos (digestão anaeróbica). Em sua composição tem-se dióxido de carbônico $\left(\mathrm{CO}_{2}\right)$, ácido sulfídrico $\left(\mathrm{H}_{2} \mathrm{~S}\right)$, oxigênio $\left(\mathrm{O}_{2}\right)$, monóxido de carbono $(\mathrm{CO})$ e metano $\left(\mathrm{CH}_{4}\right)$ (Kapdi et al., 2005; Souza et al., 2005). Alguns fatores como o $\mathrm{pH}$ influenciam no processo sendo a faixa ideal para o desenvolvimento dos microrganismos metanogênicos, entre 6,7 e 7,5 (Rajendran et al., 2012).

A Figura 1 resume as fases da digestão anaeróbica para a formação do biogás.

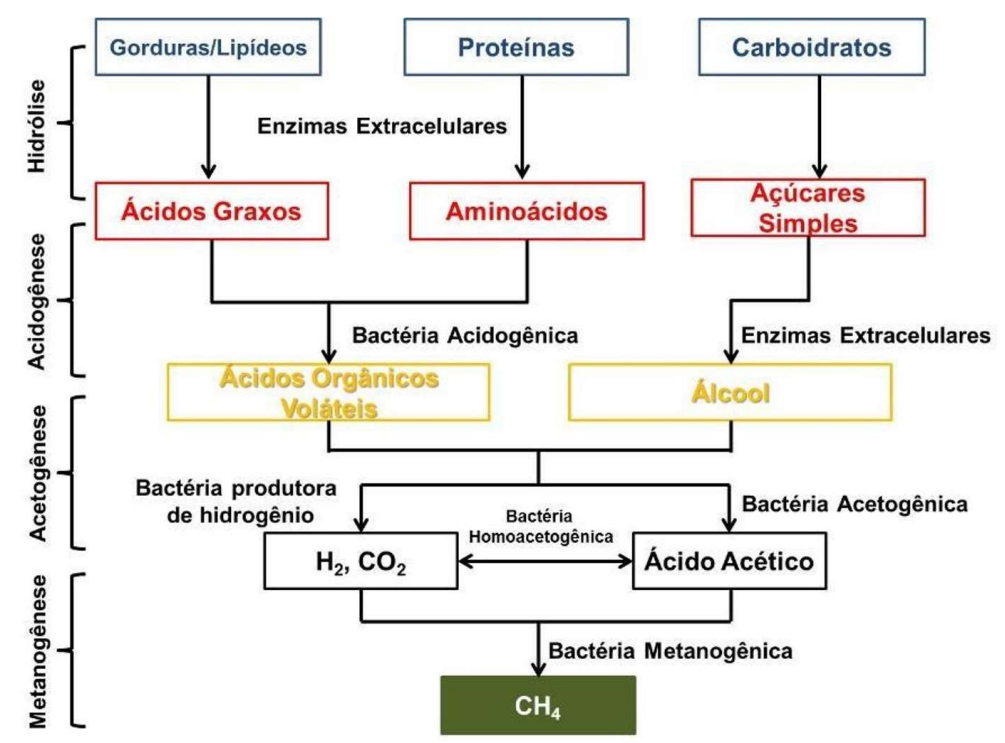

Figura 1. Fases da digestão anaeróbica. Fonte: Ferrarez et al. (2020).

A primeira fase é a hidrólise em que atuam bactérias hidrolíticas que transformam compostos orgânicos complexos, como carboidratos e proteínas, em compostos simples, como açúcares e aminoácidos. $\mathrm{Na}$ fase seguinte, a acidogênese, as bactérias acidogênicas agem formando álcoois, ácido lático e ácidos graxos de cadeia curta. A acetogênese inicia-se após a acidogênese, formando o ácido acético, hidrogênio e dióxido de carbono, devido a ação de bactérias acetogênicas. O último estágio se dá a formação do metano (CH4) pela ação das arqueas metanogênicas, que são organismos estritamente anaeróbios (Ferrarez et al., 2020).

O biogás é uma fonte de energia sustentável, renovável e de baixo custo (Carreas, 2013). É uma fonte energética pouco explorada correspondendo a apenas $0,25 \%$ de toda energia produzida no mundo (Raboni e Urbini, 2014). Após sua purificação ele dá origem ao biometano, que pode se tornar uma ótima alternativa para substituição dos combustíveis fósseis, uma vez que pode alcançar o mesmo potencial do diesel, do gás butano (gás de cozinha) e da queima de carvão mineral, que contribuem para a poluição da atmosfera e agravamento do efeito estufa, considerando a liberação de grande quantidade de $\mathrm{CO}_{2}$ (Silva e Campos, 2008; Carreas, 2013).

O objetivo desse trabalho foi avaliar a produção e o teor de metano do biogás obtido a partir da monodigestão anaeróbica de dejetos bovinos e da codigestão anaeróbica de dejetos bovinos e casca de café.

\section{Metodologia}

Os testes foram realizados no Laboratório de Biogás e Energias Renováveis (LABER) do Instituto Federal Fluminense Campus Itaperuna, na cidade de Itaperuna, estado do Rio de Janeiro.

Os substratos utilizados no experimento, dejeto bovino e casca de café foram obtidos em propriedades rurais da região Noroeste Fluminense.

Foram construídos seis digestores de bancada com materiais de baixo custo. Cada conjunto digestor foi construído com os seguintes materiais: (i) 3 tubos de PVC de $50 \mathrm{~cm}$ de comprimento e 7,5 $\mathrm{cm}$ de diâmetro; (ii) 6 tampões (caps) de PVC com 7,5 cm de diâmetro; (iii) 2 metros de mangueira de PVC transparente; (iv) cola de PVC; (v) supercola; (vi) 2 registro de saída de gás; (vii) 2 registro de saída de água. A mensuração da produção de biogás nos digestores denominados WBW (Waste-Biogas-Water) foi realizada por meio do deslocamento da água que correspondeu ao volume de biogás produzido.

A Figura 2 apresenta o esquema do digestor utilizado no experimento. No compartimento 1 (reator anaeróbico) foi colocado o volume de resíduos (substrato) conforme Tabela 1. O compartimento 2 foi preenchido totalmente com água. O compartimento 3 ficou totalmente vazio. 


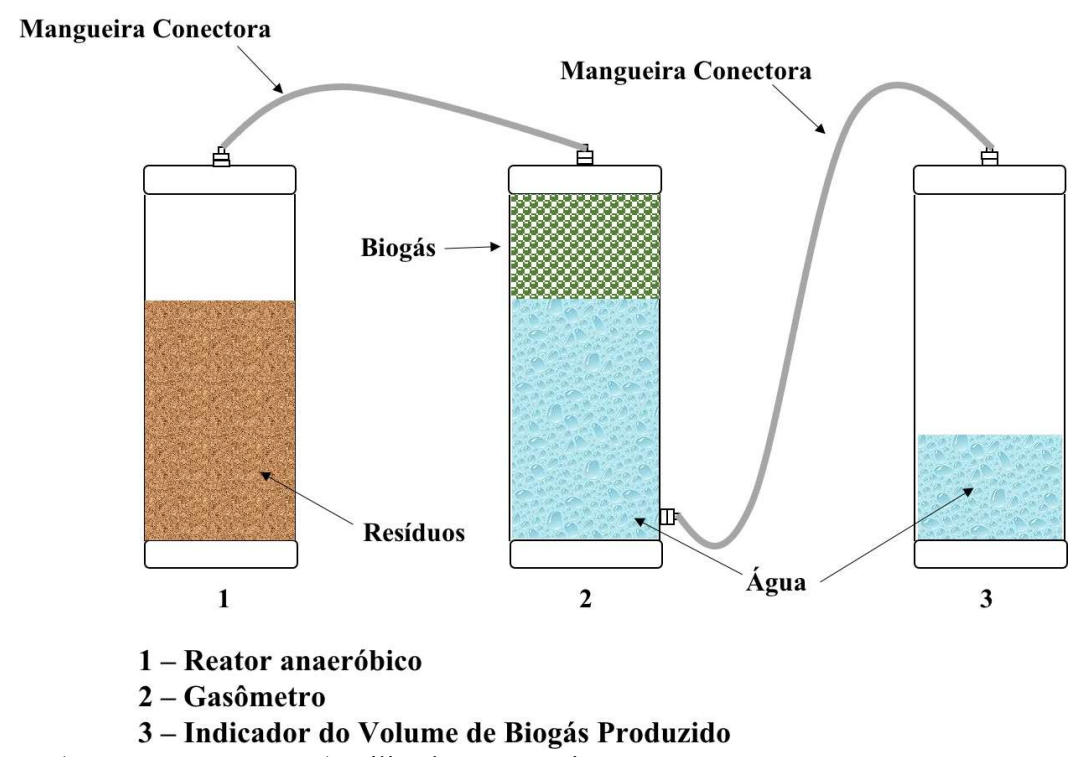

Figura 2. Digestor WBW (Waste-Biogas-Water) utilizado no experimento.

O conjunto digestor anaeróbico funciona da seguinte forma: o volume de biogás produzido no compartimento 1 é conduzido pela mangueira conectora para o compartimento 2 onde desloca para o compartimento 3 volume equivalente de água.

\subsection{Delineamento experimental}

Os seis digestores (duas triplicatas) foram carregados com os substratos nas proporções e volumes mostrados na Tabela 1 .

Tabela 1 . Tipo e volume de substratos utilizados no experimento. $\mathrm{DB}=$ Dejeto bovino, $\mathrm{PC}=\mathrm{Casca}$ de café

\begin{tabular}{cccc}
\hline Triplicatas & $\begin{array}{c}\text { Identificação } \\
\text { dos digestores }\end{array}$ & Tipo de substrato & Volume de substrato \\
\hline \multirow{2}{*}{1} & D1A & Dejeto bovino & 1 litro \\
& D1B & Dejeto bovino & 1 litro \\
& D1C & Dejeto bovino & 1 litro \\
\hline \multirow{3}{*}{2} & D2A & Dejeto bovino + Casca de café & 1 litro (DB) +1 litro (PC) \\
& D2B & Dejeto bovino + Casca de café & 1 litro (DB) +1 litro (PC) \\
& D2C & Dejeto bovino + Casca de café & 1 litro (DB) +1 litro (PC) \\
\hline
\end{tabular}

Os digestores foram operados em batelada a temperatura ambiente com tempo de retenção hidráulica (TRH) de 66 dias.

Foram realizadas leituras da produção de biogás e do teor de metano do biogás aos 7, 24, 32, 39, 45, 52, 59 e 66 dias de experimento. A aferição do volume de biogás produzido foi realizada medindo-se o volume de água deslocado no compartimento 3 do digestor WBW em cada leitura. A cada leitura da produção de biogás o volume era somado ao da leitura anterior de forma que o resultado fosse a produção acumulada ao longo do período. O teor de metano foi medido por meio de um analisador de gás da marca Sewerin modelo Multitec 545 conectado registro do gasômetro (compartimento 2) em cada leitura.

No sexagésimo sexto dia de experimento foi utilizado pHmetro de bancada para medição do $\mathrm{pH}$ do material remanescente em cada um dos digestores. As medições foram realizadas em triplicata para cada digestor.

A análise estatística dos dados obtidos neste trabalho e a construção dos gráficos com os resultados foram realizadas utilizando-se os programas Excel e Past 3.

\section{Resultados e discussões}

A Figura 3 mostra a temperatura ambiente média durante os 66 dias do experimento. 


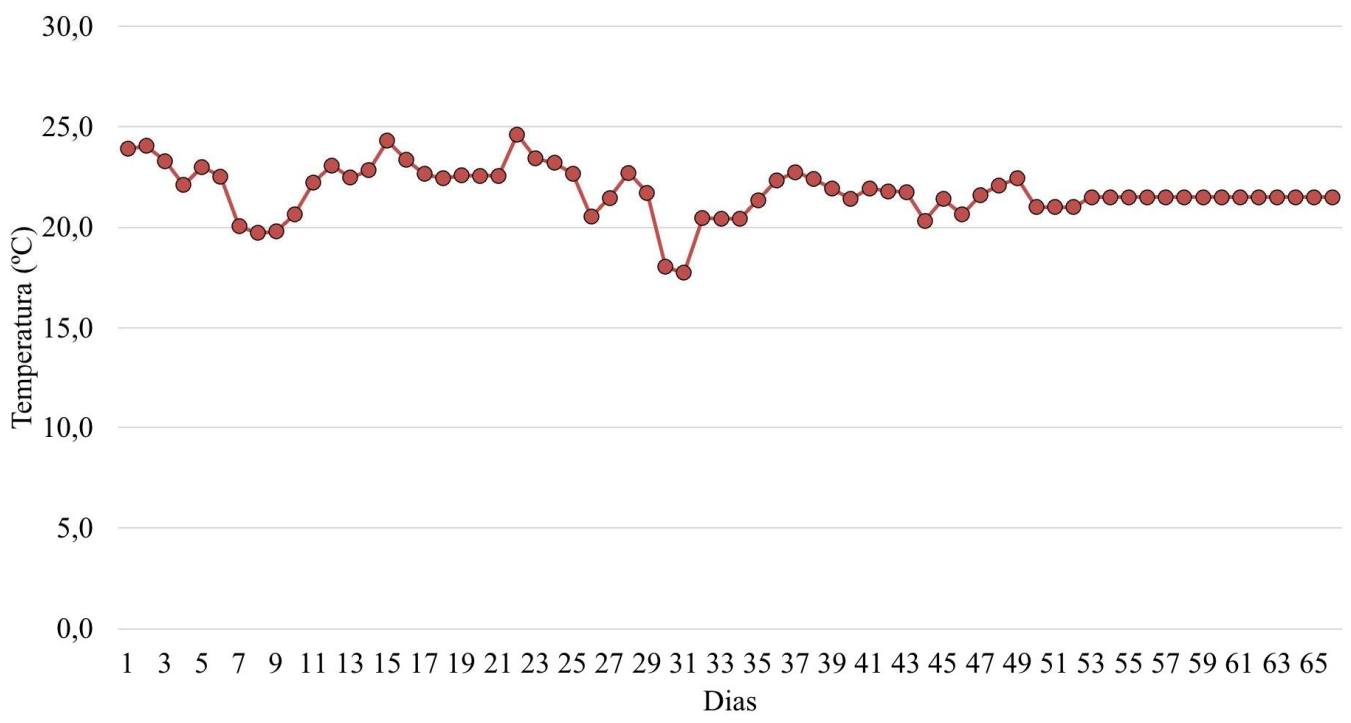

Figura 3. Temperatura local média durante a realização do experimento.

A partir da Figura 3 pode-se concluir que o processo de digestão anaeróbia ocorreu na faixa de temperatura denominada psicrofílica $\left(<25^{\circ} \mathrm{C}\right)$. O desempenho dos microrganismos não é o ideal nesta faixa de temperatura. A amplitude térmica durante o experimento foi de $6,9^{\circ} \mathrm{C}$.

A Figura 4 apresenta a produção acumulada de biogás nos digestores da triplicata D1.

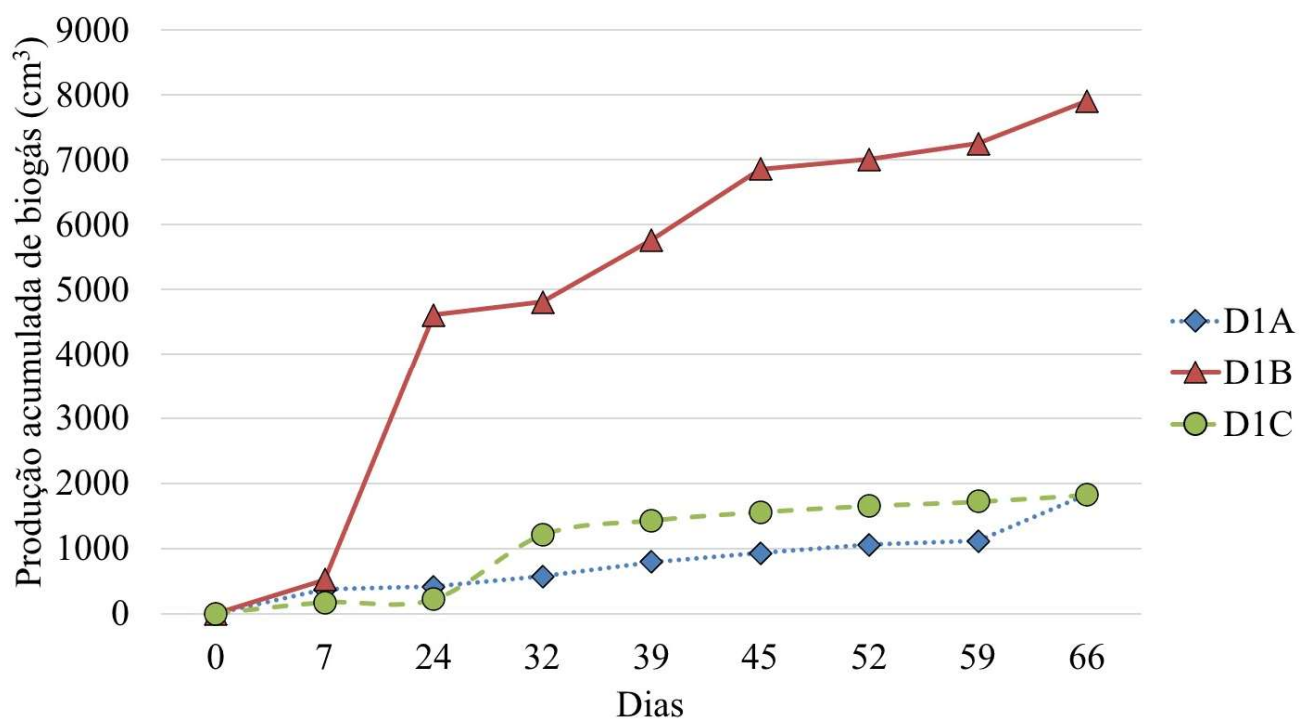

Figura 4. Produção acumulada de biogás nos digestores da triplicata D1.

Observou-se que a produção acumulada de biogás nos digestores da triplicata D1 foi semelhante nos sete primeiros dias de experimento. A partir de então a produção acumulada de biogás no digestor D1B aumentou continuamente chegando a $7.902,18 \mathrm{~cm}^{3}$ no final do experimento. Em contrapartida a produção acumulada de biogás nos digestores D1A $\left(1.828,32 \mathrm{~cm}^{3}\right)$ e D1C $\left(1.821,99 \mathrm{~cm}^{3}\right)$, ou seja, cerca de sete vezes menor que no digestor D1B aos 66 dias de experimento.

A Figura 5 apresenta a produção acumulada de biogás nos digestores da triplicata D2.

$\mathrm{O}$ digestor D2A apresentou um aumento contínuo na produção acumulada de biogás atingindo um valor de 4.911,59 $\mathrm{cm}^{3}$ ao final do experimento. O digestor D2B foi o digestor que apresentou a maior produção acumulada de biogás ao longo do experimento atingindo o valor de $12.560,48 \mathrm{~cm}^{3}$. Já o digestor D2C apresentou o pior desempenho na produção acumulada de biogás $\left(1.934,82 \mathrm{~cm}^{3}\right)$ da triplicata aos 66 dias de experimento. 


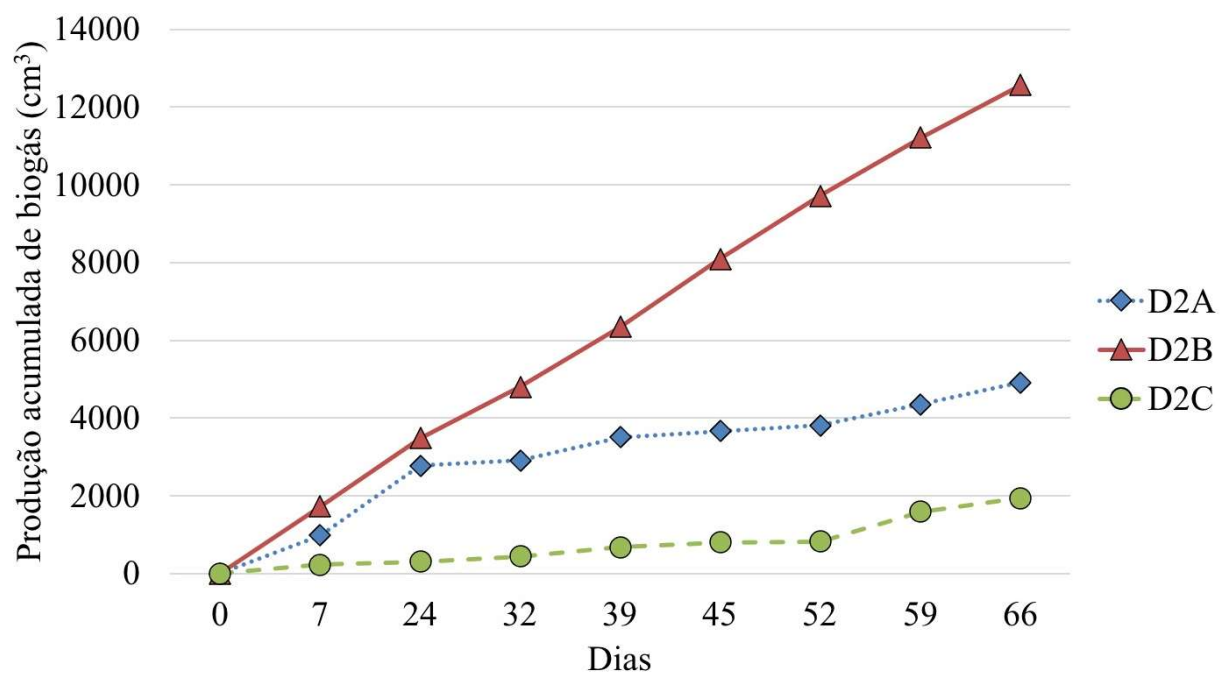

Figura 5. Produção acumulada de biogás nos digestores da triplicata D2.

A Figura 6 apresenta a concentração de $\mathrm{CH}_{4}$ nos digestores da triplicata D1.

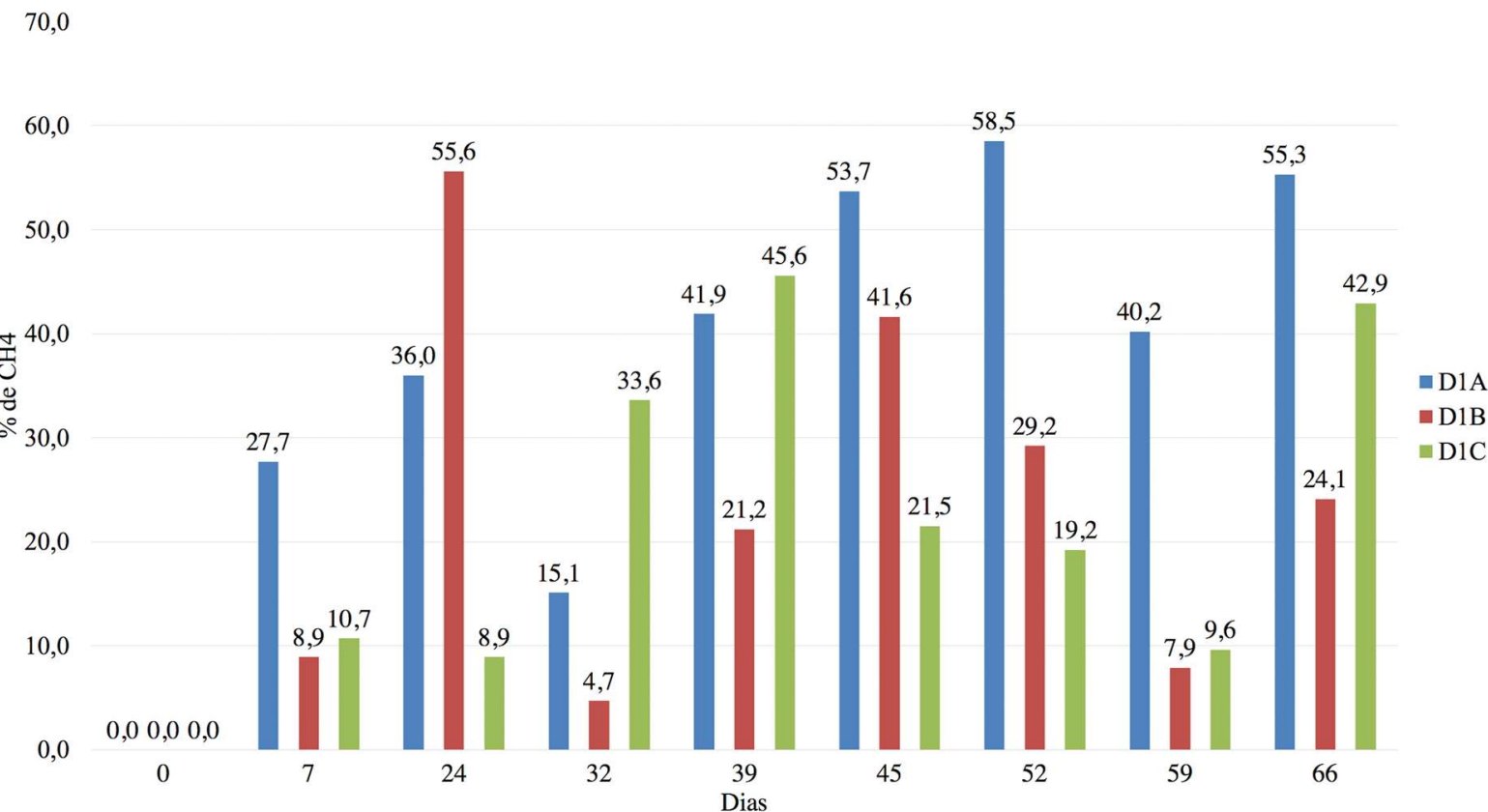

Figura 6. Concentração de metano nos digestores da triplicata D1.

$\mathrm{O}$ teor de $\mathrm{CH}_{4}$ do biogás produzido no digestor D1A variou durante o experimento apresentando valor mínimo de $15,10 \%$ aos 32 dias de experimento e máximo de $58,50 \%$ no $52^{\circ}$ dia. No digestor D1B a percentagem de $\mathrm{CH}_{4}$ no biogás produzido variou entre $4,70 \%$ ( $32^{\circ}$ dia) e $55,60 \%$ ( $24^{\circ}$ dia). O biogás produzido no digestor D1C apresentou teor de $\mathrm{CH}_{4}$ no $24^{\circ}$ dia igual a $8,90 \%$ (mínimo) e de $45,60 \%$ no $39^{\circ}$ dia.

A Figura 7 apresenta a concentração de $\mathrm{CH} 4$ nos digestores da triplicata D2.

O biogás produzido no digestor D2A apresentou teor de $\mathrm{CH}_{4}$ no $7^{\circ}$ dia de experimento igual a $17,10 \%$ (mínimo) e de $56,20 \%$ no $66^{\circ}$ dia. $\mathrm{O}$ teor de $\mathrm{CH}_{4}$ do biogás produzido no digestor D2B variou durante o experimento apresentando valor mínimo de $22,20 \%$ aos 7 dias de experimento e máximo de $65,50 \%$ no $24^{\circ}$ dia. $\mathrm{O}$ teor de $\mathrm{CH}_{4}$ do biogás produzido no digestor D2C variou durante o experimento apresentando valor mínimo de $16,90 \%$ aos 52 dias de experimento e máximo de $50,70 \%$ no $24^{\circ}$ dia. 


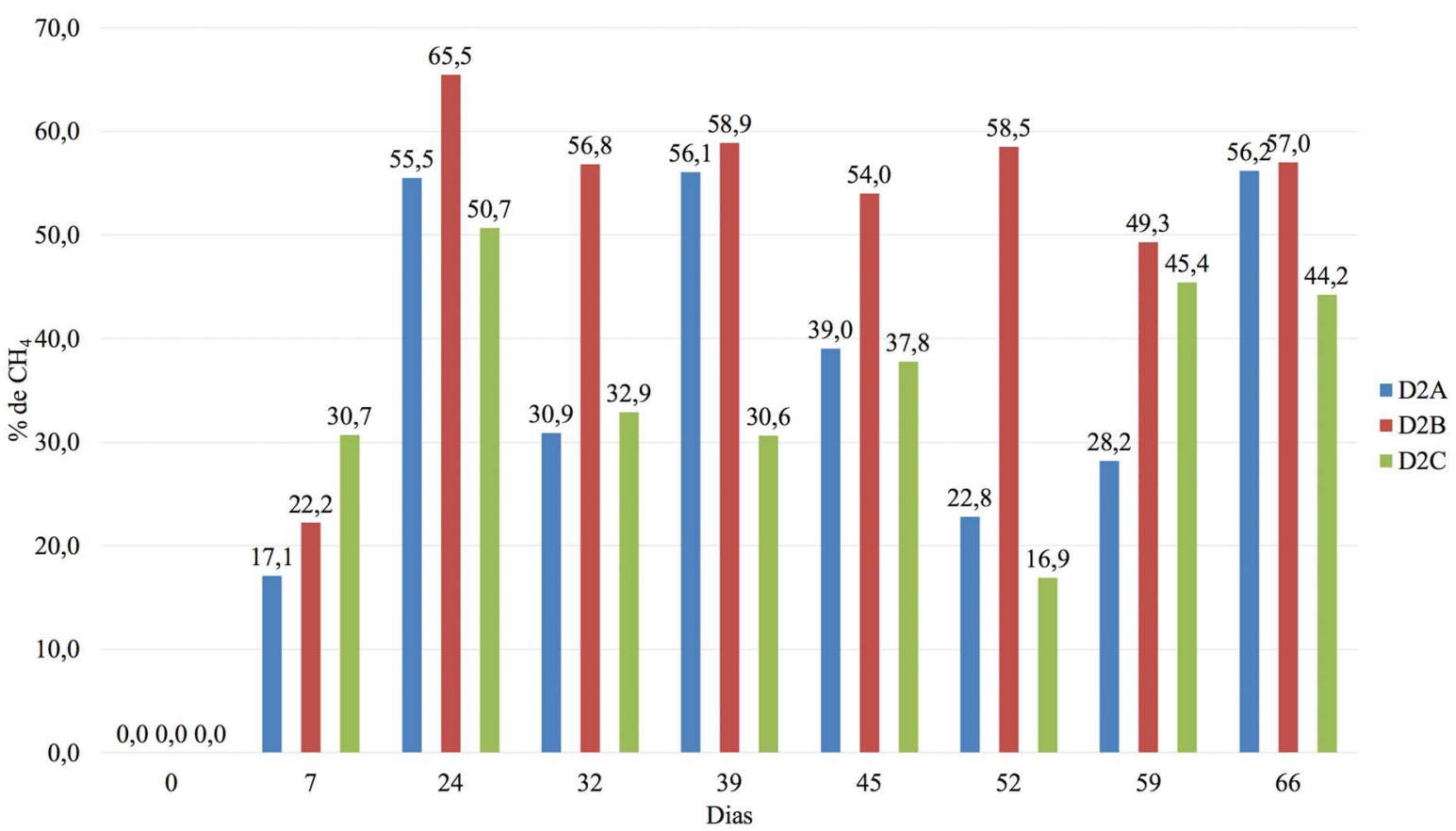

Figura 7. Concentração de metano nos digestores da triplicata D2.

A Figura 8 apresenta o $\mathrm{pH}$ medido nos digestores da triplicata D1 ao final do experimento.

Observou-se nos digestores da triplicata $\mathrm{D} 1$ que os valores do $\mathrm{pH}$ medidos ao final do experimento apresentou valores mínimos, médios e máximos na faixa ótima para a digestão anaeróbica.

A Figura 9 apresenta o $\mathrm{pH}$ medido nos digestores da triplicata D2 ao final do experimento.

Observou-se nos digestores da triplicata $\mathrm{D} 2$ que os valores do $\mathrm{pH}$ medidos ao final do experimento apresentou valores mínimos, médios e máximos na faixa ótima para a digestão anaeróbica.

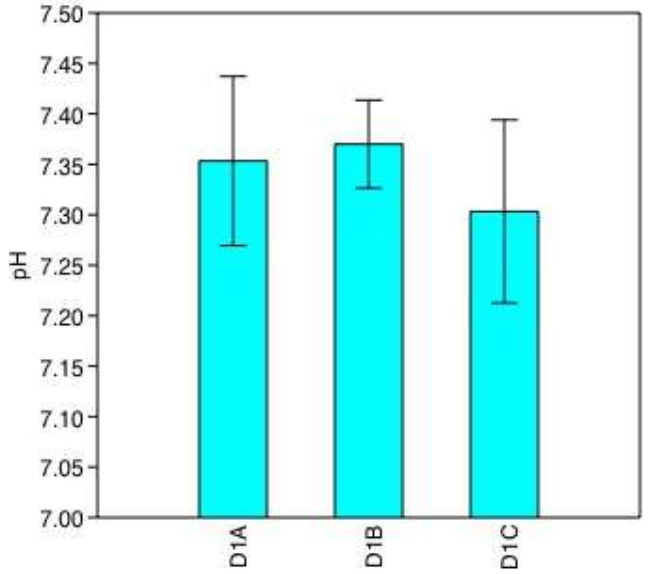

Figura 8. pH nos digestores D1A, D1B e D1C.

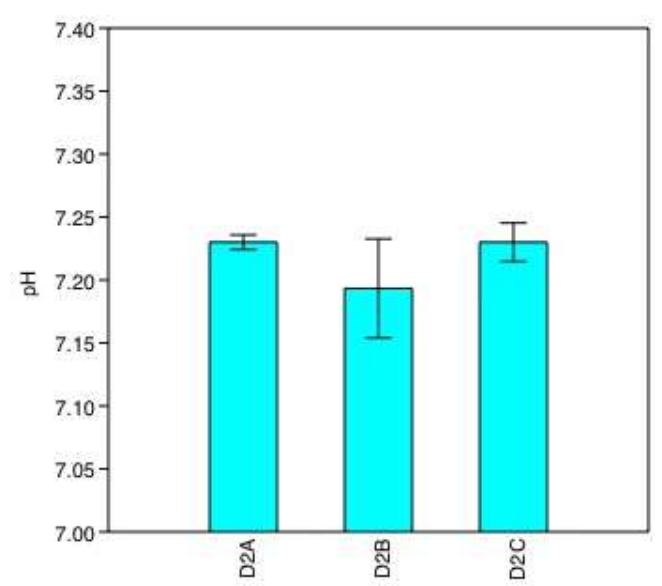

Figura 9. pH medido nos digestores D2A, D2B e D2C.

O modelo de digestor utilizado neste trabalho atendeu satisfatoriamente os objetivos propostos quais sejam: (i) garantir o ambiente anaeróbico para a realização da digestão dos resíduos agropecuários; e (ii) permitir a mensuração do volume de biogás produzido.

Em relação à produção acumulada de biogás, a triplicata D2 apresentou maior volume que a triplicata D1, o que era esperado considerando a maior quantidade de matéria orgânica na triplicata D2. Entretanto, observou-se uma diferença considerável entre os volumes de biogás produzidos entre os digestores de cada triplicata. Essa diferença pode estar associada ao fato de que fatores importantes como temperatura e $\mathrm{pH}$ não foram controlados durante o experimento.

No que diz respeito à concentração de $\mathrm{CH}_{4}$, os digestores da triplicata $\mathrm{D} 2$ apresentaram concentração média maior que os digestores da triplicata D1. Esse resultado pode estar associado ao fato de que a codigestão do dejeto bovino com casca de café contribuir no processo anaeróbico, principalmente na fase da metanogênese. 
A medição do $\mathrm{pH}$ em cada digestor ao final do experimento mostrou que os valores estavam dentro da faixa ideal para o desenvolvimento dos microrganismos. Porém, esses resultados não atestam se durante o experimento os valores de $\mathrm{pH}$ apresentaram-se favoráveis ao processo.

\section{Conclusões}

A codigestão anaeróbica se apresenta como possível solução para o tratamento de resíduos agropecuários resultando em energia renovável, o biogás, e adubo orgânico, o biofertilizante.

Os resultados obtidos neste trabalho apontaram na viabilidade da codigestão anaeróbica de dejeto bovino e casca de café considerando a complementaridade entre os resíduos para o desenvolvimento dos microrganismos responsáveis pelo processo.

Observou-se, como era esperado dada a maior quantidade de resíduo, uma produção acumulada de biogás maior na triplicata D2. Entretanto, houve uma diferença grande no volume de biogás produzido entre os digestores de uma mesma triplicata. No que diz respeito à concentração de metano, os digestores da triplicata D2 apresentaram teores médios maiores que os digestores da triplicata D1. Ao final do experimento o $\mathrm{pH}$ se apresentou na faixa ideal para o processo anaeróbico em todos os digestores.

Em trabalhos futuros seria importante realizar o controle de fatores como $\mathrm{pH}$, temperatura e agitação nos digestores de bancada.

\section{Referências bibliográficas}

Amaral, CMC, Lucas, JJ, Nascimento, AA, Ferreira, DS e Machado, MRF (2004) 'Biodigestão anaeróbia de dejetos bovinos leiteiros submetidos a diferentes tempos de retenção hidráulica'. Ciência Rural, v. 34, n. 6, pp. 1897-1902, 2004.

Carreas, N (2013) 'O Biogás: Programa de captação em energias renováveis’. ONUDI, 151p.

Fernandes, GFR e Oliveira, RA (2006) 'Desempenho do processo anaeróbio em dois estágios (reator compartimentado seguido de reator UASB) para tratamento de águas residuárias de suinocultura'. Engenharia Agrícola, v. 26, n.1, pp. 243-256.

Ferrarez, AH, Pinto, EV e Moreira, MAC (2020) 'Estado da arte da produção de biogás a partir dos resíduos do processamento da mandioca'. INOVAE - Journal of Engineering and Technology Innovation, v. 8, p. $188-208$.

Kapdi, SS, Vijay, VK, Rajesh, SK e Prasad, R (2005) Biogás Scrubing, Compression and Storage: perspective and prospectus in Indian context. Renewable Energy, v. 30, n. 8, pp. 1195-1202. <https://doi.org/10.1016/j.renene.2004.09.012>.

Kozen, EA (1983) 'Manejo e utilização de dejetos de suínos’. Concódia: Embrapa CNPSA, 32p.

Orrico, ACA, Lucas, JJ e Orrico Júnior, MAP (2007) 'Caracterização e biodigestão anaeróbia dos dejetos de caprinos'. Engenharia Agrícola, v. 27, n. 3, pp. 639-647.

Raboni, M e Urbini, G (2014) 'Produção e utilização de biogás na Europa: um levantamento da situação atual e perspectivas. Ambiente e água'. Taubaté, v. 9, n. 2, pp. 192-202. <http://dx.doi.org/10.4136/ambiagua.1324>.

Rajendran, K, Aslanzadeh, S e Taherzadeh, MJ (2012) 'Household biogas digesters - A review'. Energies, v. 5, pp. 2911-2942. <https://doi:10.3390/en5082911>.

Silva, TN e Campos, LMS (2008) 'Avaliação da produção e qualidade do gás de aterro para energia no aterro sanitário dos Bandeirantes - SP'. Engenharia Sanitária e Ambiental, v. 13, n. 1, pp. 88-96.

Souza, CF, Lucas, JJ e Ferreira, WPM (2005) 'Biodigestão anaeróbia de dejetos de suínos sob efeito de três temperaturas e dois níveis de agitação do substrato: Considerações sobre a partida'. Engenharia Agrícola, v. 25, n. 2 , pp. $530-539$. 